\title{
The Effect of the Classroom Environment on Academic Performance: Mediating Role of Learning Efficacy
}

\author{
Caiyi Jiang ${ }^{1 *}$
}

\author{
${ }^{1}$ World Leading School Association, Shanghai WLSA \\ *Corresponding author. Email: juliajiang0123@163.com
}

\begin{abstract}
The study aims to examine factors influencing children's (age 8-12) academic performance. In the article, the relationship between classroom environment and academic performance is investigated; the study self-efficacy is studied as a mediating factor. To this end, a sample of 120 children aged between 8 and 12 completed three questionnaires--My Class Inventory (MCI), Academic self-efficacy Questionnaire, and Academic Performance Rating Scale (APRS). MCI consists of three scales, including cohesiveness, satisfaction and competitiveness in measuring the classroom environment.

To analyze data, SPSS Au and descriptive statistical analysis are used. The result shows that the learning environment has a significant negative correlation with learning efficacy and academic performance. Learning efficacy is significantly negatively correlated with cohesiveness and satisfaction but not significantly correlated with competition. Academic performance is negatively correlated with cooperation and competition but not with satisfaction. Academic self-efficacy plays an important intermediary relationship between the classroom environment (cohesiveness) and academic performance. Overall, the study highlights the relationship between classroom environment and academic performance, as well as self-efficacy as mediating factor.
\end{abstract}

Keywords: Classroom environment, Academic performance, Study self-efficacy, Young children

\section{INTRODUCTION}

A lot of people care about students' academic performance. Some researches talk about factors that affect learning. Among these factors, the classroom environment has triggered many researchers' attention. There are already some studies about the classroom environment.

In the past thirty years, researchers have shown that classroom environment quality is an important determinant of students' study (Fraser, 1994, 1998a).[1] There is a concept called the psychosocial environment of the classroom, which is made up of the individuals like teachers and students in a classroom. The classroom environment usually involves the interaction between students and teachers or students and students. For academic performance, test competence is an essential factor that may help distinguish students (Sujit, 2006).[2] In one article, the author says that when students perceive the classroom positively, they will learn better (Jeffrey, 2001).[3] Meanwhile, some conclude that students familiar with smartphones will have more possibilities to achieve better academic performance (Han, 2018).[4] Classmates also affect students' academic performance. Encouragement and pressure from peers may lead students to take risky behaviors, and these actions have an indirect negative influence on their academic performance (Santor and Kusumaker, 2000).[22] Most researchers agree that students' academic performance changes with classroom conditions (Riaz, 2018).[21] Therefore, this study aims to learn the effect of the classroom environment on children's academic performance. (H1)

This study cares about whether there is a positive or negative correlation between the classroom environment and students' academic performance. Surprisingly, there are articles discussing both the bright and dark side of the classroom environment's effect on academic performance. The author is inquisitive about why there is a positive and negative correlation in different articles and thus split the dimensions of the classroom environment to study. Looking at the study of classroom environment over the past decades, the author finds various economic, effective, and widely used questionnaires, which have been developed to assess 
students' opinions toward classroom environment. Several literature reviews (Fraser, 1986, 1994, 1998; Fraser and Walberg, 1991),[6][7][8] in historical perspective, reveal that classroom environment assessments have been used as a source of dependent and independent variables in different researches in many countries. In this article, one of the most well-known assessments-My Class Inventory (MCL), is going to be used as the main source of calculating classroom environment. There are many dimensions of the classroom environment in MCL. Among different angles, the author especially focuses on the effect of students' relationships between each other and their emotion on the study. Thus, three dimensions are picked to have a close look in this study. Also, the author finds that most of the studies are focused on university students. There are not many articles studying children at primary school. The author thinks that kids' education at this age is also very important and provides the foundation for children's future. Therefore, the author decides to study children aged 8 to 12 because the author thinks the study is meaningful.

The author hopes to discover why the classroom environment can affect academic performance, so studies the mechanism behind this. Self-efficacy may influence a series of students' performances. Students who have a low self-efficacy in learning cognitive skills may avoid tasks; in contrast, students who think they are efficacious will actively participate in tasks (Dale, 1985).[9] Self-efficacy influences motivation as well. When meeting difficulties, students with high academic self-efficacy will put more effort and insist longer than children who doubt their capabilities (Bandura \& Schunk, 1981; Brown \& Inouye, 1978; Schunk, 1982).[16][11][12] Self-efficacy also affects the performance of academic skills (Schunk, 1981, 1984).[13][14] Thus, the article believes that study efficacy may affect academic performance (H2).

Self-efficacy is personal judgments of performance capabilities in a given domain of activity which includes a novel, unpredictable, and possibly stressful features (Bandura, 1977a, 1981, 1982b).[15][13][18] As cohesion and satisfaction increase, self-efficacy would increase, and as friction and difficulty decrease, self-efficacy would increase (Croissant, 2014).[19] Therefore, this research thinks that the study environment will influence the study efficacy (H3).

The author thinks that the classroom environment can affect children's learning, and academic self-efficacy has acted as an essential intermediary role between them $(\mathrm{H} 4)$.

All in all, this experiment chooses three variables: classroom environment, self-efficacy, and academic performance. This article will mainly discuss the influence of the classroom environment on students' academic self-efficacy, which, like mediation, influences academic performance. Then, we can know the effect of the classroom environment on academic performance. In the study field, academic self-efficacy means personal judgments of one's capabilities to organize and carry out serious action to achieve designated types of educational performances (Zimmerman, 1995).[20] After reading previous literature reviews on the classroom environment and academic performance, we find not many articles on the intermediate variable between them, which is self-efficacy. In one article published in Learning Environments Research, Lorsbach and Jinks (1999) pay attention to the lack of research relating psychosocial classroom environments with students' academic self-efficacy (Jeffery, 2001).[3] Therefore, this paper attempts to verify an obvious dimensionally progressive "classroom environment--> self-efficacy--> academic performance" model among the three variables. That learning efficacy has a mediating effect on the relationship between classroom environment and academic performance.

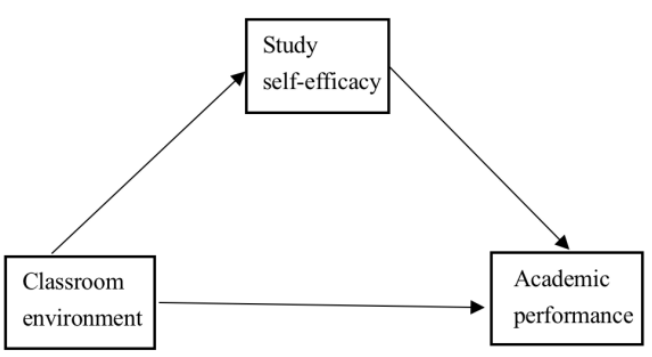

Figure 1 relationship between study environment, self-efficacy and academic performance

\section{METHOD}

\subsection{Subjects}

The study collects 120 answers to questionnaire from the internet. The questionnaire was completed anonymously. Among all subjects, there are 67 males and 53 females. The age of participants is from 8 to 12 .

\section{2. tool}

\subsubsection{Classroom environment Questionnaire}

A simplified version of the LEI, My Class Inventory (MCI), is suitable for young kids between 8 and 12 years old. The original form of the MCI includes 38 items altogether (six about Cohesiveness, eight about Friction, eight about Difficulty, nine about Satisfaction, and seven about competitiveness). This study takes three items of them (Cohesiveness, competitiveness, and sanctification). MCI uses a two-point (Yes-No) response format. There is one point for yes while no point for no. Its Cronbach $\alpha$ coefficient is 0.793 . This number is 
larger than 0.7 , which means that the reliability of the data is good.

\subsubsection{Academic self-efficacy Questionnaire}

It contains two items: "learning ability self-efficacy" and "study behavioral efficacy." It uses Five-point integration. Subjects respond to each question with a number between 1 (never or poor) and 5 (very often or excellent).

\subsubsection{Academic performance rating scale}

Academic Performance Rating Scale (APRS), a 19-item scale, will reflect children's academic performance and abilities in classroom settings. Two more items were added to assess the frequency of staring episodes and social withdrawal. Subjects answer every question using a Likert scale format from 1 (never or poor) to 5 (very often or excellent). Seven APRS items (i.e., 12,13,15-19) are reverse-keyed in scoring to ensure a higher total score corresponds to a positive academic status.

\subsection{Testing procedures and data processing}

Researchers send the link to the questionnaire in social media like WeChat and websites like Credamo. SPSS Au was used for descriptive statistical analysis and bootstrap analysis.

\section{RESULT}

\subsection{Descriptive statistic}

In table 1, the learning environment has a significant negative correlation with learning efficacy and academic performance.

As there are three items in the classroom environment, the author uses descriptive statistical analysis to study three items (Cohesiveness, competitiveness, and satisfaction), respectively.

As can be seen from table 2, learning efficacy is significantly negatively correlated with cohesiveness and satisfaction but not significantly correlated with the competition. 'Academic performance is negatively correlated with cooperation and competition, but not with satisfaction.

Table 1. relationship between classroom environment, study self-efficacy and academic performance

\begin{tabular}{lllll}
\hline Variables & $M \pm S D$ & 1 & 2 & 3 \\
\hline 1.Classroom environment & $29.145 \pm 3.472$ & 1 & & \\
2.Study self-efficacy & $75.109 \pm 14.811$ & $-0.236^{*}$ & 1 & \\
& & & & \\
3.Academic performance & $65.427 \pm 9.31$ & $-0.252^{* *}$ & $0.548^{* *}$ & 1
\end{tabular}

Table 2. relationship between classroom environment, study self-efficacy and academic performance

\begin{tabular}{|c|c|c|c|c|c|c|}
\hline Variables & $\mathrm{M} \pm \mathrm{SD}$ & 1 & 2 & 3 & 4 & 5 \\
\hline $\begin{array}{l}\text { 1.Classroom environment } \\
\text { ( Cohesiveness) }\end{array}$ & $8.782 \pm 1.517$ & 1 & & & & \\
\hline $\begin{array}{l}\text { 2.Classroom environment } \\
\text { ( Competitiveness ) }\end{array}$ & $8.518 \pm 1.38$ & $0.260^{\star *}$ & 1 & & & \\
\hline $\begin{array}{l}\text { 3.Classroom environment } \\
\text { ( Satisfaction ) }\end{array}$ & $11.845 \pm 1.638$ & $0.299 * \star$ & $0.451^{\star \star}$ & 1 & & \\
\hline 4.Study self-efficacy & $75.109 \pm 14.811$ & $-0.303^{* *}$ & -0.129 & $-0.191^{\star}$ & 1 & \\
\hline 5.Academic performance & $65.427 \pm 9.31$ & $-0.241^{\star}$ & $-0.264^{\star \star}$ & -0.137 & $0.548^{\star \star}$ & 1 \\
\hline
\end{tabular}

According to table 2, the author finds that between the classroom environment (cohesiveness) and the academic performance, the academic self-efficacy may play an important intermediary relationship. 


\subsection{Mediating effect test}

\subsubsection{Learning self-efficacy partially mediates} the influence of learning environment on academic performance

Taking classroom environment as the independent variable (x), learning efficacy as the intermediary variable (m), and academic performance as the dependent variable (y), the data were statistically analyzed by using the mediation test in SPSS Au. It can be seen from Table 3 that the coefficient $\mathrm{C}$ is -1.018 , and the t-test difference of paired samples is significant, $\mathrm{t}(109)=-4.266, \mathrm{P}<.001$. The coefficient $\mathrm{a}$ is -1.359 , the difference of paired samples t-test is significant, $t$ $(109)=-3.493, \mathrm{P}<.001$. The coefficient $\mathrm{B}$ was 0.382 , and the difference of t-test between paired samples was significant, $\mathrm{t}(109)=8.242, \mathrm{P}<$. 001. The significance of the coefficient product $\mathrm{AB}$ is directly tested by the nonparametric percentile bootstrap method with deviation correction. The sample size is set as 5000 , and the default degree of the confidence interval is $95 \%$. Results as shown in table 4 , the $95 \%$ confidence interval of intermediary effect $\mathrm{AB}$ is $[-0.388 \sim-0.028]$, a and $\mathrm{B}$ are significant, the direct effect $\mathrm{C}$ 'is $-0.46, \mathrm{P}>05$, and $\mathrm{a} * \mathrm{~B}$ is negative just as $\mathrm{C}$. It is a partial mediating effect. Effect ratio: $\mathrm{a} * \mathrm{~B} / \mathrm{C}=51.025 \%$.

Table 3. Coefficient test

\begin{tabular}{|c|c|c|c|c|c|c|}
\hline & \multirow{2}{*}{ Effect } & \multirow{2}{*}{ SE } & \multirow{2}{*}{ T value } & \multirow{2}{*}{ df } & \multicolumn{2}{|c|}{ T-value $95 \%$ confidence interval } \\
\hline & & & & & Lower limit & Upper limit \\
\hline The coefficient c & -1.018 & 0.239 & $-4.266^{\star \star}$ & 109 & -1.486 & -0.551 \\
\hline The coefficient a & -1.359 & 0.389 & $-3.493^{\star \star}$ & 109 & -2.122 & -0.597 \\
\hline The coefficient $b$ & 0.382 & 0.046 & $8.242^{\star \star}$ & 109 & 0.291 & 0.473 \\
\hline
\end{tabular}

Table 4. Mediation effect test based on Bootstrap method

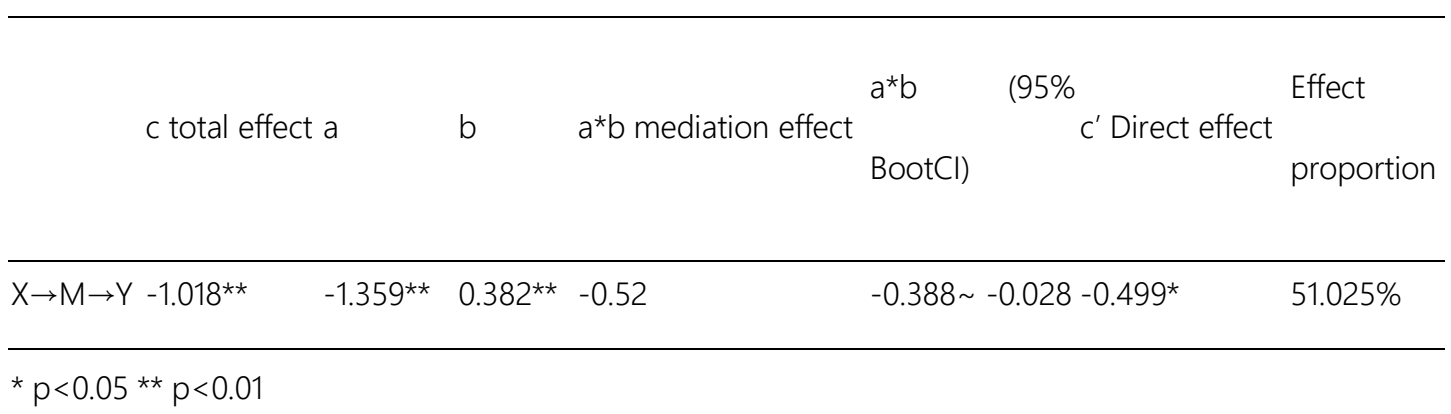

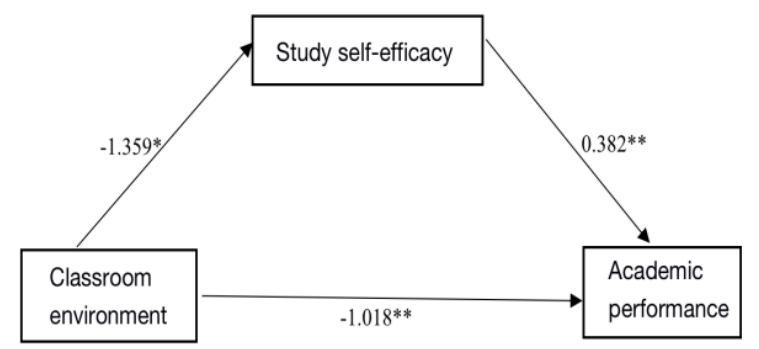

Figure 2 The mediating effect of perceived learning self-efficacy on the impact of classroom environment on academic performance
3.2.2 Learning self-efficacy plays a significant mediating role in the influence of cohesiveness in learning environment cohesiveness on academic performance

Taking classroom environment (cohesiveness) as the independent variable (x1), study self-efficacy as the intermediary variable $(\mathrm{m})$, and academic performance as the dependent variable (y), the data were statistically analyzed by using the mediation test in SPSS Au. It can be seen from Table 5 that the coefficient $\mathrm{C}$ is -1.881 , and the t-test difference of paired samples is significant, $\mathrm{t}(109)=-3.346, \mathrm{P}<.001$. The coefficient $\mathrm{a}$ is -2.837 , and the difference of paired sample t-test is significant, $t$ $(109)=-3.155, \mathrm{P}<.001$. The coefficient $\mathrm{B}$ was 0.397 , and the difference of t-test between paired samples was significant, $\mathrm{t}(109)=8.503, \mathrm{P}<.001$. The significance 
of the coefficient product $A B$ is directly tested by the nonparametric percentile bootstrap method with deviation correction. The sample size is set as 5000 and the default degree of the confidence interval is $95 \%$. Results as shown in Table 6, the $95 \%$ confidence interval of intermediary effect $\mathrm{AB}$ is [-0.375 -0.032], a and $\mathrm{B}$ are significant, and the direct effect $\mathrm{C}$ 'is -0.755 , $\mathrm{P}>$. 05, indicating that the intermediary effect is significant and it is a complete intermediary.

Table 5. Coefficient test

\begin{tabular}{|c|c|c|c|c|c|c|}
\hline & \multirow{2}{*}{ Effect } & \multirow{2}{*}{ SE } & \multirow{2}{*}{ T value } & \multirow{2}{*}{ df } & \multicolumn{2}{|c|}{ T-value $95 \%$ confidence interval } \\
\hline & & & & & Lower limit & Upper limit \\
\hline The coefficient $c$ & -1.881 & 0.562 & $-3.346^{\star *}$ & 109 & -2.983 & -0.779 \\
\hline The coefficient a & -2.837 & 0.899 & $-3.155^{\star \star}$ & 109 & -4.599 & -1.075 \\
\hline The coefficient $b$ & 0.397 & 0.047 & $8.503^{\star \star}$ & 109 & 0.306 & 0.489 \\
\hline
\end{tabular}

Table 6. Mediation effect test based on Bootstrap method

\begin{tabular}{|c|c|c|c|c|}
\hline c Total effect & $b$ & $a \star b$ Mediating effect & $\begin{array}{lr}a * b & \left(95 \% C^{\prime} \quad \text { Direct }\right. \\
\text { BootCl }) & \text { effect }\end{array}$ & $\begin{array}{l}\text { Effect } \\
\text { proportio } \\
\text { n }\end{array}$ \\
\hline $\mathrm{X} 1 \rightarrow \mathrm{M} \rightarrow \mathrm{Y}-1.881^{\star \star}$ & $-2.837^{\star *} 0.397^{\star *}$ & +1.126 & $-0.375 \sim-0.032-0.755$ & $100 \%$ \\
\hline
\end{tabular}

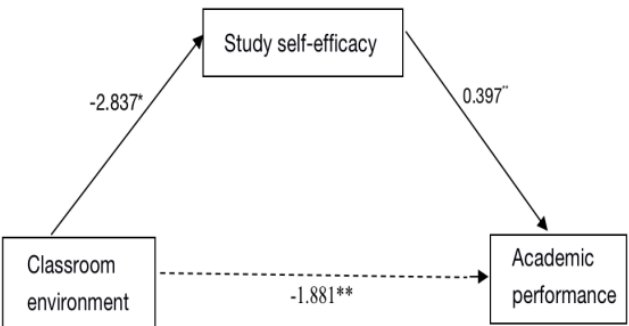

Figure 3 The mediating role of perceived self-efficacy in the impact of learning environment (cooperation) on academic performance

\section{DISCUSSION}

\subsection{The relationship between environment and academic performance}

The study finds that the learning environment has a significant negative correlation with academic performance. To be specific, academic performance would be better in the lower learning environment. This result verifies hypothesis 1 . This is consistent with the results of previous studies (Sunyoung, 2018).[4] However, it contradicts Jeffrey's idea that students learn better when they perceive the classroom environment positively (Jeffrey, 2001).[3] The author decides to study the items of the classroom environment to find the factor that influences the result. The author looks from three items: cohesiveness, competitiveness and satisfaction. Among them, cohesiveness plays an important role here. Santor and Kusumaker also believe that peers' cohesiveness may have a negative indirect effect on academic achievement (Santor and Kusumaker, 2000).[22] This may be because when children gather together, they tend to be influenced by bad habits. Thus they cannot think independently, which is an essential factor to achieve academic success. Therefore, for high academic performance, a good classroom environment and thinking independently are both important.

\subsection{The mediating role of study self-efficacy}

This study finds that the study self-efficacy partially mediated the relationship between the classroom environment and academic performance. It completely mediated the relationship between cohesiveness and academic performance. Therefore, Self-efficacy is an important influence mechanism of how the learning environment influences academic performance. This is consistent with the views of predecessors. This may be because when students' are closer and cooperate, they will have more confidence. Being encouraged by others or supported by the belief to prove themselves, students will challenge themselves more and think they can do it. 


\subsection{Significance and limitations of the study}

According to the study of the relationship among classroom environment, study self-efficacy and academic performance, teachers can get inspiration to improve their teaching strategy. Children can also have a positive influence on their studies. In addition, few people are studying the mediating effect of academic self-efficacy. Thus this study is meaningful in the exploration of new factors and connections.

However, this study still has some limitations. Because of the problem of time and money, this study uses convenience sampling. Collecting online and having only 120 answers, our analytic result is limited by the data.

In the future, there could be more studies on this topic, and by using more extensive and reasonable sampling methods, the result can be more valid.

\section{CONCLUSION}

(1) Classroom learning environment has a negative effect on children's academic achievement.

(2) Study efficacy may positively affect academic performance.

(3) Study environment will negatively influence the study efficacy.

(4) Classroom environment can affect children's learning and academic self-efficacy has acted as an important intermediary role between them.

\section{REFERENCES:}

[1] Fraser, Barry J, Assessment of Learning Environments: Manual for Learning Environment Inventory (LEI) and My Class Inventory (MCI). Third Version., Feb 82,

[2] Sujit S. Sansgiry, PhD, Monali Bhosle, MS, and Kavita Sail, MS, October 15, 2006, Factors That Affect Academic Performance Among Pharmacy Students, American Journal of Pharmaceutical Education 2006; 70 (5) Article 104

[3] JEFFREY P. DORMAN, 2 May 2001, ASSOCIATIONS BETWEEN CLASSROOM ENVIRONMENT AND ACADEMIC EFFICACY, Learning Environments Research 4: 243-257, 2001.

[4] Han, Sunyoung, and Yong Jeong Yi. "How Does the Smartphone Usage of College Students Affect Academic Performance?" Wiley Online Library, John Wiley \& Sons, Ltd, 19 Sept. 2018, onlinelibrary.wiley.com/doi/10.1111/jcal.12306.
[5] BARRY J. FRASER, 1998, CLASSROOM ENVIRONMENT DEVELOPMENT, VALIDITY AND APPLICATIONS, Learning Environments Research 1: 7-33, 1998.

[6] Fraser, B.J. \& Walberg, H.J. (Eds.). (1991). Educational environments: evaluation, antecedents and consequences. London: Pergamon. Fraser, B.J. (1986). Classroom environment. London: Croom Helm

[7] Fraser, B.J. (1994). Research on classroom and school climate. In D. Gabel (Ed.), Handbook of research on science teaching and learning (pp. 493541). New York: Macmillan.

[8] Fraser, B.J. (1998). Science learning environments: Assessment, effects and determinants. In B.J. Fraser \& K.G. Tobin (Eds.), International handbook of science education (pp. 527-564). Dordrecht, The Netherlands: Kluwer.

[9] DALE H. SCHUNK, 22, April 1985, SELF-EFFICACY AND CLASSROOM LEARNING, BNS-8011753.

[10] BANDURA, A, \& SCHUNK, D. H. (1981). Cultivating competence, self-efficacy, and intrinsic interest through proximal self-motivation. Journal of Personalily and Social Psychology, 41, 586-598.

[11] BROWN, I., JR., \& INOUYE, D. K. (1978). Learned helplessness through modeling: The role of perceived similarity in competence. Journal of Personality and Social Psychology, 36, 900-908.

[12] SCHUNK, D. H. (1982). Effects of effort attributional feedback on children's perceived self-efficacy and achievement. Journal of Educational Psychology, 74, 548-556.

[13] SCHUNK, D. H. (I98 1). Modeling and attributional effects on children's achievement: A self-efficacy analysis. Journal of Educational Psychology, 73, 93-105.

[14] SCHUNK, D. H. (1984). Self-efficacy perspective on achievement behavior. Educational Psychologist, 19,48- 58 .

[15] BANDURA, A. (1977a). Self-efficacy: Toward a unifying theory of behavioral change. Psychological Review, 84, 191-215

[16] BANDURA, A. (1981), Self-referent thought: A developmental analysis of self-efficacy. In J. H. Flavell \& L.

[17] Ross (Eds.), Social cognitive development: Frontiers and possible futures (pp.200-239) Cambridge, England: Cambridge University Press. 
[18] BANDURA, A. (1982b). Self-efficacy mechanism in human agency. American Psychologist, 37, 122-147.

[19] Croissant, H. (2014). Classroom environment influence on student self-efficacy in mathematics. Texas A \& M University Commerce. Retrieved from http://gradworks.umi.com/36/20/3620807.html

[20] Zimmerman, B. J. (1995). Self-efficacy and educational development. In A. Bandura (Ed.), Self-efficacy in changing societies (pp. 202-231). New York: Cambridge University Press.

[21] Riaz Hussain Malik* and Asad Abbas Rizvi, August 2018, Effect of Classroom Learning Environment on Students' Academic Achievement in Mathematics at Secondary Level, Bulletin of Education and Research Vol. 40, No. 2 pp. 207-218

[22] Santor, D., Deanne, M. \& Kusumskur, V. (2000). Measuring peer pressure. A popularity and conformity in adolescent boys and girls: predicting school performance, sexual attitude and substance abuse. Journal of youth and adolescent, 29(2), 163. 